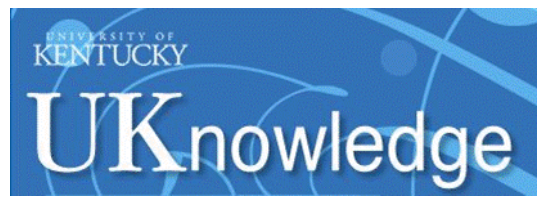

University of Kentucky

UKnowledge

Biosystems and Agricultural Engineering Faculty Publications

\title{
Fourth-Generation Fan Assessment Numeration System (FANS) Design and Performance Specifications
}

\author{
Michael P. Sama \\ University of Kentucky, michael.sama@uky.edu \\ George B. Day \\ University of Kentucky, george.day@uky.edu \\ Laura M. Pepple \\ Puck Custom Enterprises \\ Richard S. Gates \\ University of Illinois at Urbana-Champaign
}

Follow this and additional works at: https://uknowledge.uky.edu/bae_facpub

Part of the Agriculture Commons, Bioresource and Agricultural Engineering Commons, Computer Sciences Commons, and the Electro-Mechanical Systems Commons

Right click to open a feedback form in a new tab to let us know how this document benefits you.

\section{Repository Citation}

Sama, Michael P.; Day, George B.; Pepple, Laura M.; and Gates, Richard S., "Fourth-Generation Fan Assessment Numeration System (FANS) Design and Performance Specifications" (2017). Biosystems and Agricultural Engineering Faculty Publications. 137.

https://uknowledge.uky.edu/bae_facpub/137

This Article is brought to you for free and open access by the Biosystems and Agricultural Engineering at UKnowledge. It has been accepted for inclusion in Biosystems and Agricultural Engineering Faculty Publications by an authorized administrator of UKnowledge. For more information, please contact UKnowledge@lsv.uky.edu. 


\section{Fourth-Generation Fan Assessment Numeration System (FANS) Design and Performance Specifications}

\section{Digital Object Identifier (DOI)}

https://doi.org/10.13031/trans.12119

\section{Notes/Citation Information}

Published in Transactions of the ASABE, v. 60, issue 2, p. 507-516.

(C) 2017 American Society of Agricultural and Biological Engineers

The copyright holder has granted the permission for posting the article here. 


\title{
FOURTH-GENERATION FAN ASSESSMENT NUMERATION SYSTEM (FANS) DESIGN AND PERFORMANCE SPECIFICATIONS
}

\author{
M. P. Sama, G. B. Day, L. M. Pepple, R. S. Gates
}

\begin{abstract}
The Fan Assessment Numeration System (FANS) is a measurement device for generating in situ ventilation fan performance curves. Three different-sized FANS currently exist for assessing ventilation fans commonly used in poultry and livestock housing systems. All FANS consist of an array of anemometers inside an aluminum shroud that traverse the inlet or outlet of a ventilation fan. The FANS design has been updated several times since its inception and is currently in its fourth-generation (G4). The current design iteration (FANS-G4) is reported in this article with an emphasis on the hardware and software control, data acquisition systems, and operational reliability. Six FANS-G4 units were fabricated at the University of Kentucky (UK) Agricultural Machinery Research Laboratory and calibrated at the University of Illinois UrbanaChampaign (UIUC) Bioenvironmental and Structural Systems (BESS) Laboratory. Results demonstrated that the FANS-G4 was capable of measuring volumetric airflow to within $0.6 \%$ of full-scale (FS), which ranged from 15,000 to 56,000 $\mathrm{m}^{3} \mathrm{~h}^{-1}$.
\end{abstract}

Keywords. Airflow, Calibration, Computer software, Emissions, FANS, Instrumentation.

$\mathrm{F}$ an performance curves are used to select fans as well as estimate ventilation rates in poultry and livestock housing systems. Over time, the actual fan performance degrades from the manufacturer's specifications due to normal wear, and thus the ventilation rate decreases (Person et al., 1979). Furthermore, building ventilation rate is a key component in accurate determination of building emissions (Calvet et al., 2013; Cortus et al., 2012; Gates et al., 2009), and FANS have been used as parts of systems for measuring emissions of greenhouse gases (Burns et al., 2008a; Hayes et al., 2013), ammonia (Gates et al., 2005; Liang et al., 2005; Wheeler et al., 2006; Burns et al., 2007), volatile organics (Trabue et al., 2013), non-methane hydrocarbons ( $\mathrm{Li}$ et al., 2008), and particulate matter (Burns et al., 2008b). Indoor air pollutant concentrations in these studies were monitored using devices similar to those reported by Ji et al. (2016) and Gates et al. (2005) or with real-time systems of different configurations (Heber et al., 2009; Moody et al., 2008). Regardless, the building ventilation rate was computed using real-time building static pressure measurements and fan performance curves for the spe-

Submitted for review in October 2016 as manuscript number PAFS 12119; approved for publication by the Plant, Animal, \& Facility Systems Community of ASABE in February 2017.

The authors are Michael P. Sama, ASABE Member, Assistant Professor, and George B. Day, ASABE Member, Agriculture Research Specialist, Department of Biosystems and Agricultural Engineering, University of Kentucky, Lexington, Kentucky; Laura M. Pepple, ASABE Member, Project Engineer, Puck Custom Enterprises, Manning, Iowa; Richard S. Gates, ASABE Fellow, Professor, Department of Agricultural and Biological Engineering, University of Illinois, Urbana, Illinois. Corresponding author: Michael P. Sama, 119 C.E. Barnhart Building, University of Kentucky, Lexington, KY 40546; phone: 859-218-4325; e-mail: michael.sama@uky.edu. cific building that were developed with the FANS. The resultant measurements of concentration and ventilation were used to estimate the housing emission rate (Gates et al., 2005, 2009; Moody et al., 2008; Calvet et al., 2013). FANS have been used primarily in emissions research, as noted above, but have also been used in energy efficiency evaluations (Lopes et al., 2010; Zhi et al., 2015), to evaluate building configuration effects on in situ fan performance (Purswell et al., 2014; Simmons et al., 1998b), as a reference standard for other in situ methods (Liang et al., 2016), to visualize fan airflows (Sama et al., 2012a), and in different configurations including upstream, downstream, and adjacent to other operating fans (Morello et al., 2014; Li et al., 2009).

Simmons et al. (1998a) first published the concept of a device for in situ measurement of volumetric flow rate from ventilation fans. The device consisted of a horizontal array of anemometers inside an aluminum shroud that vertically traversed the inlet or outlet of a $122 \mathrm{~cm}$ (48 in.) ventilation fan. The original design was refined by Gates et al. (2004) to include an updated data acquisition system and was manufactured at the University of Kentucky (UK) for researchers throughout the U.S. studying emissions from poultry housing systems. The updated design, called the Fan Assessment Numeration System (FANS), is referred to as FANS-G2 in this study. The next design iteration (FANS-G3) included additional FANS unit sizes to better accommodate $76 \mathrm{~cm}$ (30 in.) and $137 \mathrm{~cm}$ (54 in.) ventilation fans (Sama et al., 2008). In addition to multiple-size units (fig. 1), FANS-G3 replaced the outdated commercial data acquisition system used in FANS-G2 with a custom embedded controller. The FANSG3 embedded controller processed all anemometer voltages on board and used digital serial data transmission to pass anemometer and control data between the FANS-G3 and a personal computer (PC), instead of the parallel analog and dig- 


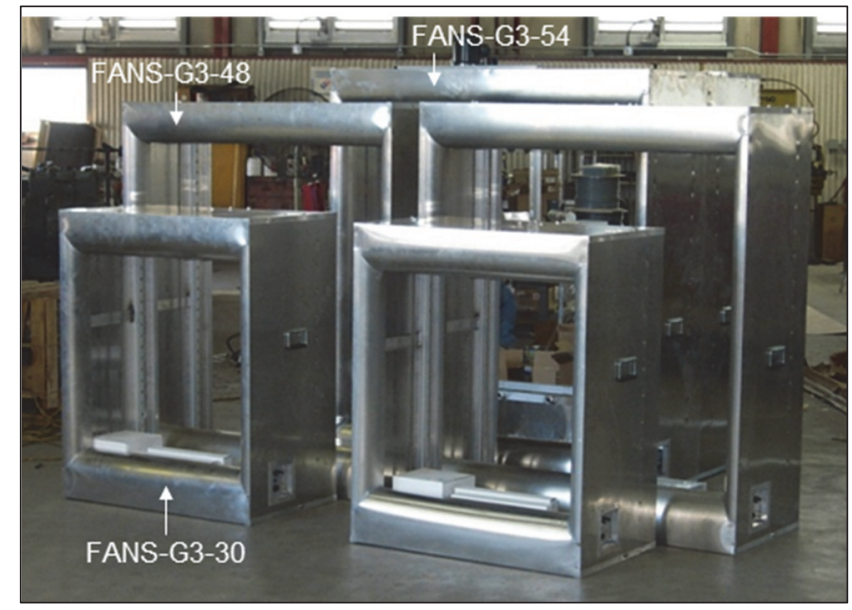

Figure 1. Three models of third-generation FANS (FANS-G3) units for in situ volumetric airflow measurements on $76 \mathrm{~cm}(30$ in.), $122 \mathrm{~cm}$ (48 in.), and $137 \mathrm{~cm}(54 \mathrm{in}$.$) size ventilation fans.$

ital connections to a PCMCIA card used in FANS-G2. All FANS-G2 units were upgraded to the FANS-G3 controller and recalibrated at the University of Illinois Urbana-Champaign (UIUC) Bioenvironmental and Structural Systems (BESS) Laboratory, resulting in 27 upgraded and newly manufactured FANS-G3 units in 2007. Four of the FANSG2 and FANS-G3 units were calibrated multiple times over a ten-year period to determine calibration drift (Sama et al., $2012 b$ ). Results showed three of the four units retained their original accuracy, while one unit degraded over time with anemometer wear. Replacement of the worn anemometer fixed the issue but demonstrated the need for regular testing and re-calibration to ensure accurate field measurement.

The most recent design iteration (FANS-G4) was completed in 2011 and included an overall upgrade of the electromechanical components to make the unit safer and faster to use while retaining the same basic functionality as previous generation FANS. Five FANS-G4 were manufactured and one FANS-G3 was upgraded to the latest design. Five of the units were calibrated at the UIUC BESS Laboratory in December 2011 (Sama et al., 2012b), and the final unit was calibrated at the UIUC BESS Laboratory in September 2016. The objectives of this study were to (1) document the FANSG4 hardware and software control and data acquisition components and (2) evaluate the FANS-G4 airflow measurement performance through laboratory calibration.

\section{Materials ANd Methods HARDWARE COMPONENTS}

The FANS-G4 uses a horizontal array of propeller anemometers (27106T, R.M. Young Co., Traverse City, Mich.) mounted on a rack that is driven vertically by lead screws and supported by linear guide rails on both ends (fig. 2). One lead screw is coupled to a single-phase alternating current (AC) motor through a right-angle gearbox, and the second lead screw is coupled to the first through a chain drive at the top of the unit. The rate of travel is nominally designed to be $1.5 \mathrm{~cm} \mathrm{~s}^{-1}$, which is approximately twice the speed of the FANS-G3. The motor is controlled by an embedded system

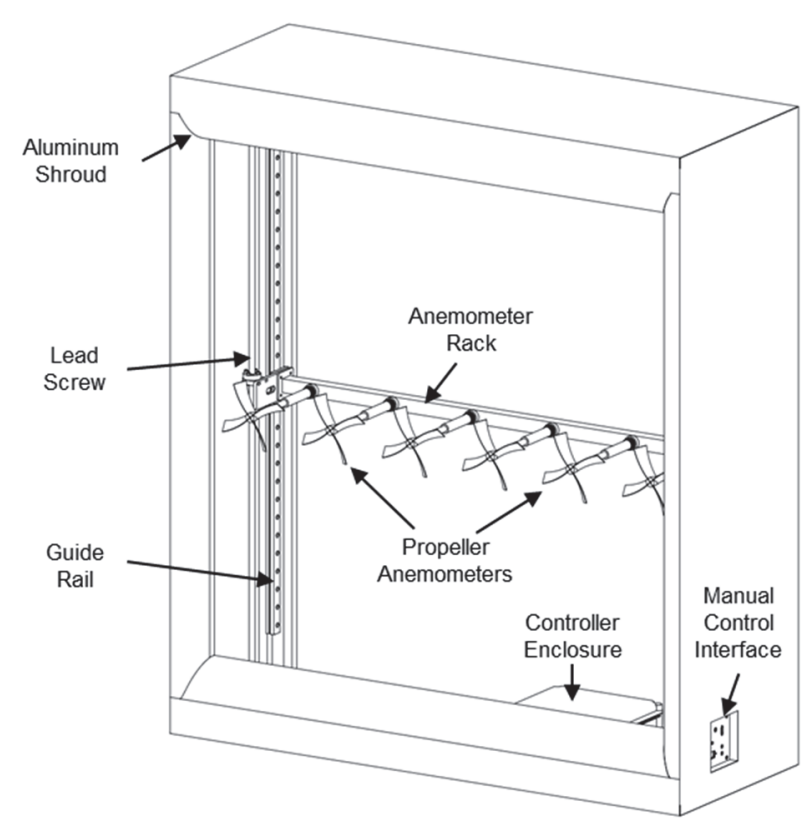

Figure 2. Major hardware components of the FANS-G4 (motor, chain drive, and limit switches not shown).

located inside the controller enclosure. The manual control interface provides power entry, a switch for the system to be turned on/off, and a switch to manually move the anemometer rack up or down. The entire system is surrounded by an aluminum shroud to form a seal against a ventilation fan mount. The shroud has rolled inlet surfaces to guide airflow into the unit.

The main hardware control components include an embedded controller that samples anemometer voltages, transmitted data to and received command inputs from a personal computer (PC), and an electromechanical system to drive the $\mathrm{AC}$ motor and provide status inputs to the embedded controller.

\section{EMBEDDED CONTROLLER}

The FANS-G4 embedded controller is built around a 16bit digital signal processor (DSP) (dsPIC30F4013, Microchip Technology, Inc., Chandler, Ariz.) on a custom printed circuit board (PCB) interface (fig. 3). The PCB interface in-

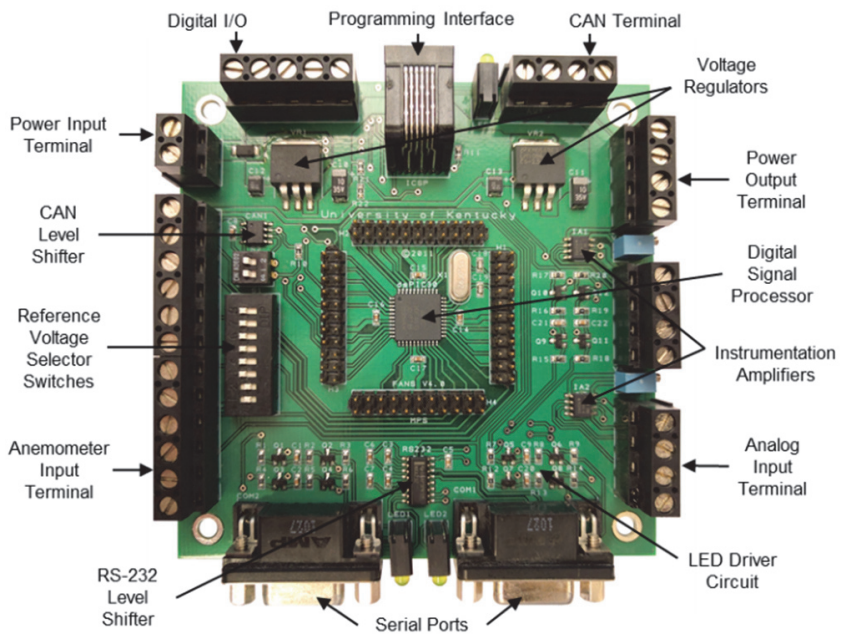

Figure 3. FANS-G4 controller PCB with major components. 
tegrates supporting components, including voltage regulators, level shifters, terminals, and connectors, into a single device. The controller is designed to be powered by a 12 VDC supply and regulates the supply voltage to 5.0 and 2.5 VDC for powering circuit components. The controller is programmed using the in-circuit serial programming (ICSP) interface on the DSP through a six-pin RJ-11 connector.

Each anemometer is connected to a separate analog-todigital (A/D) input on the DSP and supplied with a 2.5 VDC reference voltage via the anemometer input terminal. The reference voltage provides a bias that allows negative airflow to be measured, which has been noted to occur around the edges of ventilation fans operating against a high static pressure or in turbulent upstream situations. The A/D inputs are configured with 12-bit resolution and a $5 \mathrm{~V}$ dynamic range between 0 and $5 \mathrm{VDC}$.

Digital input/outputs (DI/O) sense the status of the upper and lower limit switches and control the motor via solid-state and mechanical relays. Two serial ports transmit data and receive control inputs on the DSP's universal asynchronous receiver transmitters (UARTs) through an RS-232 level shifter. A controller area network (CAN) interface and two additional analog inputs connected to instrumentation amplifiers are also included for future use but are not implemented in the operation of the FANS-G4.

\section{ELECTROMECHANICAL SYSTEM}

The FANS-G4 electromechanical system serves as an interface between the embedded controller and the drive motor (fig. 4). A combination of solid-state (SS) relays (G4ODC5 and G4IDC5, Opto 22, Temecula, Cal.) and double-pole double-throw (DPDT) mechanical relays (T92S11D22-12, TE Connectivity, Schaffhausen, Switzerland) converts the 5 VDC digital output signals on the embedded controller to the 12 VDC signals used to trigger the mechanical relays and the $120 \mathrm{VAC}$ used to power the motor. Typically, a threewire capacitor-start motor and gearbox derived from a $2200 \mathrm{~N}$ electric linear actuator are used, which requires a common neutral and selectively enabled hot connections to operate. Alternately, a four-wire capacitor-start motor may be used but requires an adjustment in the relay wiring to control the motor winding polarity.

Limit switches (SZL-VL-A, Honeywell, Morris Plains, N.J.) provide signals when the anemometer rack reaches the top or bottom of the unit and prevent the rack from overtraveling the linear guide. The limit switches have normally open (NO) and normally closed (NC) circuits. Control inputs to the motor relays pass through the $\mathrm{NC}$ circuit. When a limit switch is tripped, the NC circuit is broken and the control input can no longer activate the motor relay in that direction. The 12 VDC power supply is connected to one end of the NO circuit, and the other end is connected to a digital input on the embedded controller via an SS relay. The low-voltage

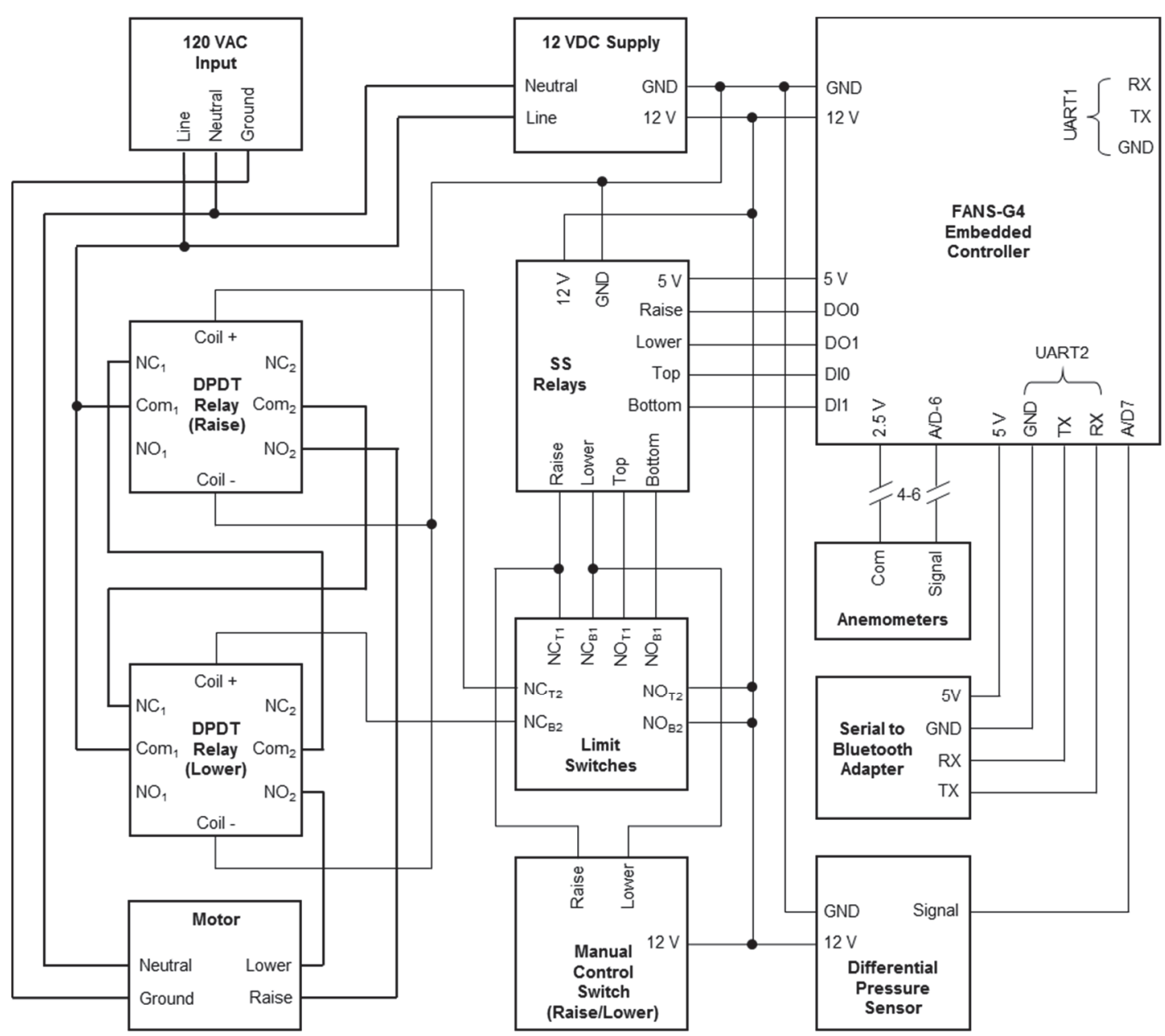

Figure 4. FANS-G4 electromechanical schematic. Bold lines are high-voltage signals. Power switch, fuses, and status LEDs are not shown. 
signaling used in the limit switches is a safety improvement over the FANS-G2 and FANS-G3 units. The previous design passed the AC line voltage from the mechanical relays to the motor through the limit switches, which potentially exposed the operator to high-voltage wiring outside of the control box.

Additional components include a differential pressure sensor (2651R25WD2BT1G, Setra, Boxborough, Mass.) for measuring building static pressure; a 12 VDC power supply (HC12-3.4-A+G, SL Power Electronics, Ventura, Cal.) for powering the embedded controller, mechanical relays, limit circuits, and pressure sensor; terminal strips for providing voltage busses and connections between components inside the controller enclosure and external devices; an RS-232 serial connection to a Bluetooth adapter (SB0011-S1, SIIG, Inc., Fremont, Cal.) for providing a wireless interface between the embedded controller and a PC; and a fuse to protect the DC side of the electromechanical system. The differential pressure sensors integrated into the FANS-G4 units are factory calibrated with specified accuracy of $\pm 1 \%$ fullscale (FS).

A manual control interface is located on the side of the unit and provides switches for turning the unit on and moving the anemometer rack, a serial port connector for wiring the unit directly to a PC, quick-disconnect air line couplings for supplying a differential pressure signal, LEDs for indicating $\mathrm{AC}$ and DC power, and a fuse to protect the $\mathrm{AC}$ side of the electromechanical system.

\section{SOFTWARE COMPONENTS}

\section{Communication Protocol}

The FANS-G4 has two software components, one for the embedded controller and the other for the PC. The software components communicate using ASCII serial data strings to transmit anemometer data from the FANS-G4 to the PC and control commands from the PC to the FANS-G4 (fig. 5). Individual string elements are separated by commas, and the string is terminated with a checksum and the non-printable carriage return and line feed characters. The checksum is a two digit-hexadecimal representation of the bit-wise exclusive-OR operation of every 8-bit ASCII character between the $\$$ character and asterisk $\left({ }^{*}\right)$.

The data string is composed of an identifier, four binary bits for indicating limit switch and relay status, six four-digit decimal numbers for individual anemometer speeds in revolutions per minute (rpm), one four-digit decimal number for the differential pressure sensor in millivolts $(\mathrm{mV})$, and the two-digit hexadecimal checksum. The anemometer speed data elements are signed decimal numbers and include the negative digit when airflow is reversed. The last one and two anemometer speed data elements are ignored by the PC soft- ware for $122 \mathrm{~cm}$ (48 in.) and $76 \mathrm{~cm}$ (30 in.) FANS-G4 units, respectively, because no anemometers are connected to the corresponding analog-to-digital (A/D) inputs. The data string is transmitted at a $12.5 \mathrm{~Hz}$ interval, which is a $67 \%$ increase in the FANS-G3 data rate.

The command string is composed of an identifier, a onedigit decimal number for the command type, and the twodigit hexadecimal checksum. Three possible commands can be sent from the PC to the FANS-G4 to stop, raise, and lower the anemometer rack, which correspond to decimal numbers 0,1 , and 2, respectively. The serial port settings are 19,200 baud, eight data bits, no parity, one stop bit, and software flow control.

\section{Embedded Controller Software}

The FANS-G4 embedded controller software is written in C (C30, Microchip Technology, Inc., Chandler, Ariz.) and includes four source files that perform data output, command input, and motor control tasks (fig. 6). The MAIN source file configures the DSP, handles serial command receive interrupts, compiles the serial data strings, controls the digital output states for operating the motor, and monitors the digital inputs for the position status of the anemometer rack. $M A I N$ relies on the other three source files: $R S 232, A N A$ $L O G$, and $C H E C K S U M$. RS232 serves as the receiver buffer to compile and search the serial data strings transmitted from the PC to the FANS-G4. A valid data string is defined to start with the $\$$ character and end with the line-feed character. Once a valid data string is found, it is passed back to MAIN for determining if the string is formatted correctly for the FANS-G4 unit and to process the corresponding command. $A N A L O G$ serves as a function to simplify accessing the A/D hardware and to facilitate oversampling of the analog inputs for noise reduction. Each A/D result is the average of 32 successive samples. CHECKSUM serves as a function to calculate the checksum from the incoming or outgoing serial data streams.

\section{PC Software}

The FANS-G4 PC software is written in Visual Basic (Microsoft Corp., Redmond, Wash.). It serves as a virtual operator interface for running the FANS-G4 unit and as a data logger for compiling and storing measurements. The PC software consists of a menu structure, status bar, and six tabbed pages within a single Windows form (fig. 7). The File menu provides a method for exiting the program. The Settings menu provides options for choosing the default folder to store logged data, provides the file name schema for logged data files, and displays measurements in U.S. customary or SI units. The Help menu provides access to a PDF copy of the FANS-G4 user manual. The status bar contains text-based indications for serial port connectivity, limit
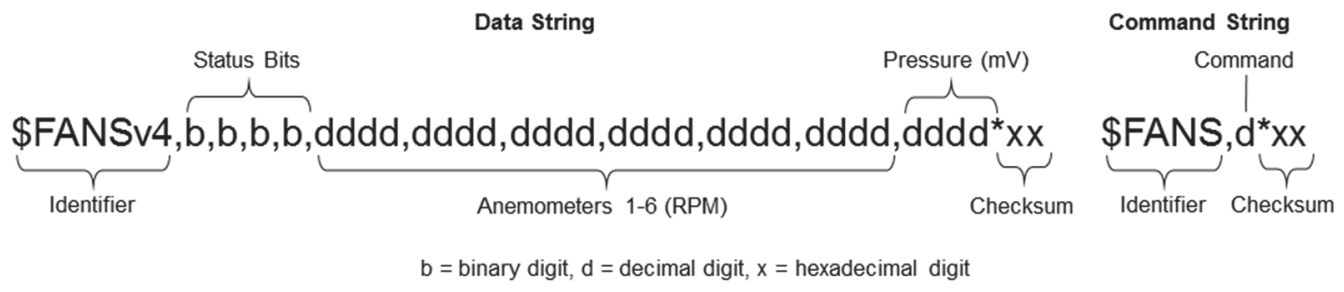

Figure 5. FANS-G4 serial data string format. 

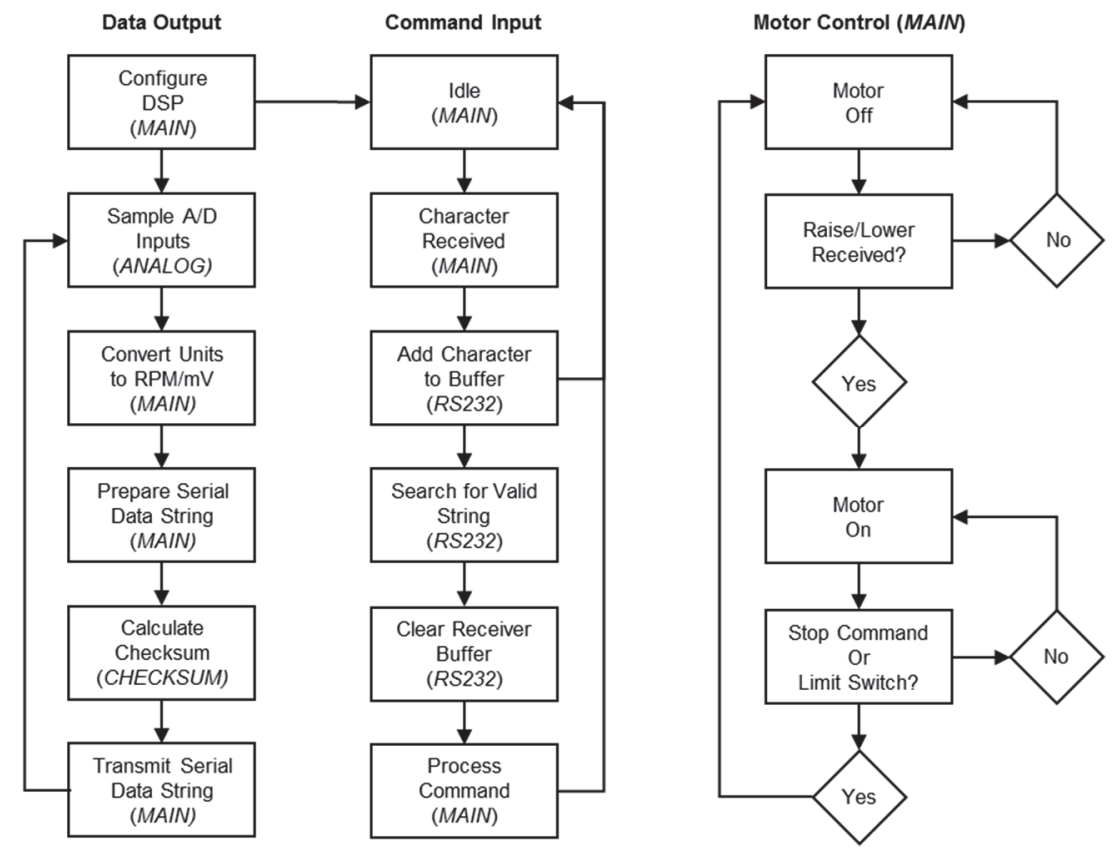

Figure 6. Flow diagram of the embedded controller software showing the interactions of subroutines between the MAIN, RS232, ANALOG, and CHECKSUM source files.
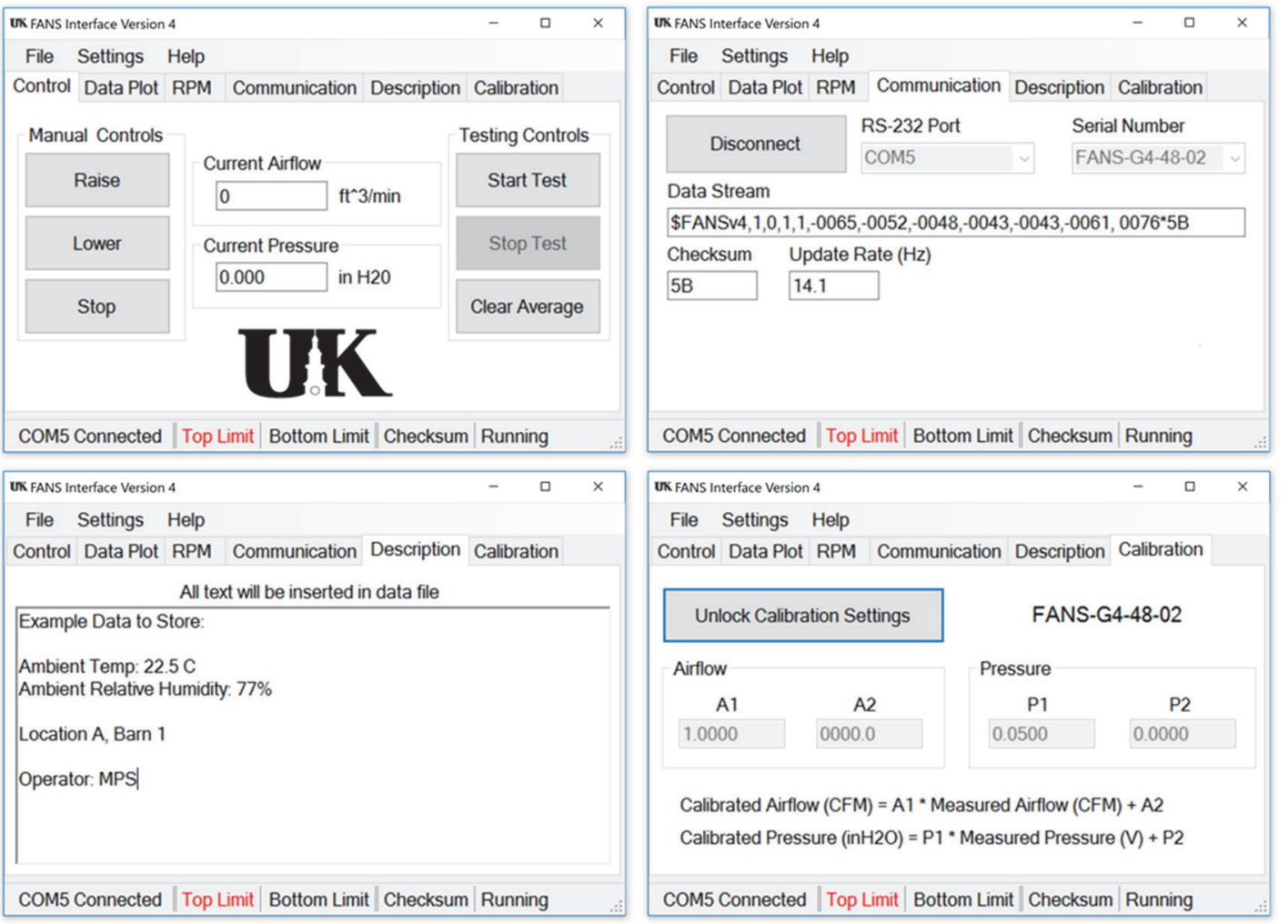

Figure 7. FANS-G4 PC software tabs for control, communication, description, and calibration (data plot and $R P M$ tabs are not shown).

switch status, data validity, and if the FANS-G4 motor is running.

The Control tab is the primary user interface during FANS-G4 operation and includes buttons for manually raising, lowering, and stopping the unit, buttons for starting and stopping a test, a button for clearing a test average, and numeric displays for instantaneous airflow and pressure. A test is defined as a full measurement cycle in which the anemometer rack starts at either the top or bottom and runs until it reaches the opposite end. Therefore, the Start Test button is only enabled when the anemometer rack is triggering one of the limit switches, and the Stop Test button is only enabled when a test is underway. Upon completing a test, the airflow and pressure text boxes display the average data for the en- 
tire test. The Data Plot tab provides a graph of the volumetric airflow rate and static pressure over a 50-sample interval. The $R P M$ tab plots the individual anemometer rotational speeds (rpm) over a 50-sample interval. The Communication tab allows the user to select the serial communication port on the PC and the FANS serial number setting. Once configured, the PC software automatically connects using the previously selected port and serial number settings. The raw data string is also displayed along with a locally calculated checksum for validating the data string and an approximate measurement of the data update rate. The Description tab provides a text box for inserting notes into the recorded data files. The Calibration tab allows the user to modify the default calibration settings for a particular FANS unit by serial number. By default, the PC software applies a scale of 1 and offset of 0 to the airflow measurement. The nominal calibration for the differential pressure sensor voltage is $12.4 \mathrm{~Pa}$ $\left(0.050\right.$ in. $\left.\mathrm{H}_{2} \mathrm{O}\right)$ per volt and is adjustable. Calibration settings in this tab are permanently stored by the PC program. The PC software is backward compatible with the FANSG3, which used a different data structure and serial port settings, as documented by Sama et al. (2008).

\section{Output File}

A completed test produces a single comma separated values (CSV) text file containing the summary and raw data (fig. 8). The file location and base file name previously defined are automatically appended by an ascending integer number to ensure that no data are overwritten. The summary data include the FANS serial number, date, time, average airflow, average pressure, calibration settings, and descriptive text. The raw data list individual anemometer rotational speeds (rpm) and pressure measurements. The raw data are included primarily for diagnostic purposes to help identify anemometer issues but are also useful for visualizing air velocity variations through the FANS unit.

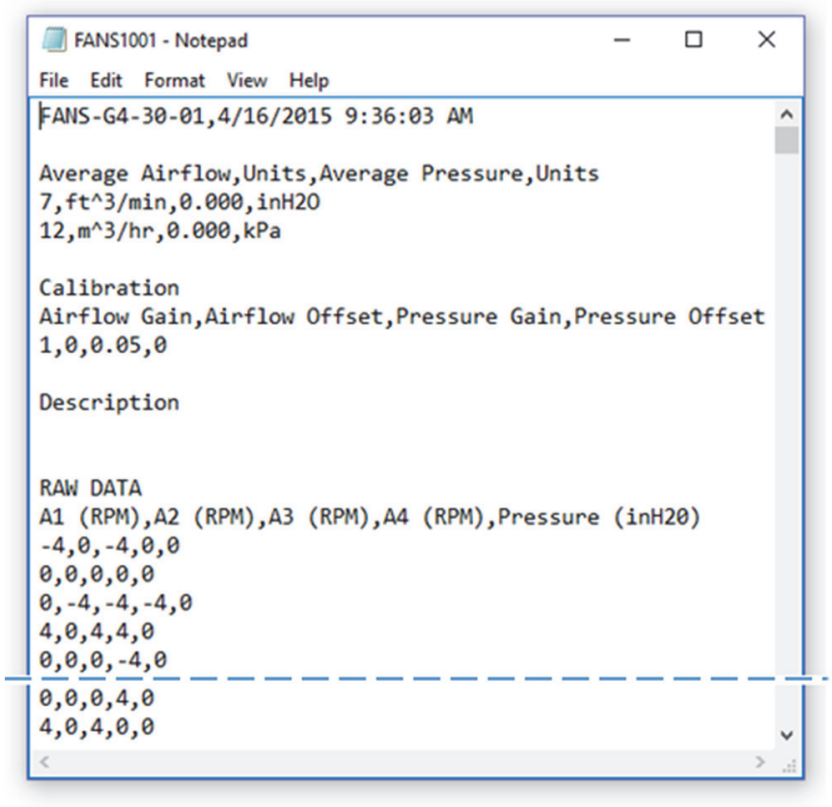

Figure 8. Example FANS-G4 data output file.

\section{Airflow Calculations}

Conversion of the voltages at individual anemometers to the volumetric flow rate used in a fan curve occurs in two stages. The first stage occurs in the embedded controller software, where the DSP converts the analog input voltages to a digital count using a 12-bit successive approximation $\mathrm{A} / \mathrm{D}$ converter. The difference between the $\mathrm{A} / \mathrm{D}$ result for each anemometer and the reference voltage is converted to rpm as an integer value using the nominal relationship between anemometer voltage and speed provided by the manufacturer (eq. 1):

$$
S=\frac{\left(C_{1}-C_{2}\right) \times 3600 \times 5}{4095}
$$

where

$$
\begin{aligned}
& S=\text { anemometer rotational speed }(\mathrm{rpm}) \\
& C_{1}=\mathrm{A} / \mathrm{D} \text { digital count from anemometer voltage } \\
& C_{2}=\mathrm{A} / \mathrm{D} \text { digital count from reference voltage } \\
& 3600=\text { nominal rpm per } \mathrm{V}\left(\mathrm{rpm} \mathrm{V} \mathrm{V}^{-1}\right) \\
& 5=\text { full scale A/D range }(\mathrm{V}) \\
& 4095=\text { maximum A/D count value }\left(2^{12}-1\right) .
\end{aligned}
$$

The second stage occurs in the PC software, where the rpm measurements from all anemometers are converted to instantaneous velocity, averaged, and multiplied by the inlet dimensions, resulting in the average volumetric flow rate (eq. 2):

$$
\bar{F}=\frac{1}{M \times N} \times \sum_{m=1}^{M} \sum_{n=1}^{N} \frac{\left(S_{m, n} \times 0.00490\right)}{3600} \times I
$$

where

$$
\begin{aligned}
& \bar{F}=\text { average volumetric flow rate }\left(\mathrm{m}^{3} \mathrm{~h}^{-1}\right) \\
& M=\text { number of anemometers } \\
& N=\text { number of rpm measurements } \\
& m=\text { anemometer index } \\
& n=\text { rpm measurement index } \\
& I=\text { inlet cross-sectional area }\left(\mathrm{m}^{2}\right) \\
& 0.00490=\text { nominal air velocity per } \mathrm{rpm}_{\left(\mathrm{m} \mathrm{s}^{-1} \mathrm{rpm}^{-1}\right)} \\
& 3600=\text { number of seconds in an hour }\left(\mathrm{s} \mathrm{h}^{-1}\right) .
\end{aligned}
$$

The calibrated volumetric flow rate is determined by applying the airflow calibration coefficients previously described in the Calibration tab of the PC software (eq. 3):

$$
\bar{F}_{C}=A_{1} \times \bar{F}+A_{2}
$$

where

$$
\begin{aligned}
& \bar{F}_{C}=\text { calibrated average volumetric flow rate }\left(\mathrm{m}^{3} \mathrm{~h}^{-1}\right) \\
& A_{1}=\text { calibration slope }(\text { dimensionless }) \\
& A_{2}=\text { calibration offset }\left(\mathrm{m}^{3} \mathrm{~h}^{-1}\right) .
\end{aligned}
$$

The pressure sensor signal is similarly converted from a voltage to differential pressure in two stages. The first stage occurs in the embedded controller software, where the DSP converts the $A / D$ result to $m V$ as an integer value by multiplying the $\mathrm{A} / \mathrm{D}$ result by the full-scale $\mathrm{A} / \mathrm{D}$ range in $\mathrm{mV}$ and dividing by the maximum $\mathrm{A} / \mathrm{D}$ digital count value (eq. 4): 


$$
\Delta P=\frac{C_{3} \times 5000}{4095}
$$

where

$$
\begin{aligned}
& \Delta P=\text { differential pressure signal }(\mathrm{mV}) \\
& C_{3}=\mathrm{A} / \mathrm{D} \text { digital count from pressure sensor voltage } \\
& 5000=\text { full scale } \mathrm{A} / \mathrm{D} \text { range }(\mathrm{mV}) .
\end{aligned}
$$

The second stage occurs in the PC software, where the differential pressure signal in $\mathrm{mV}$ is converted to $\mathrm{Pa}$ using the pressure calibration coefficients previous described in the Calibration tab of the PC software (eq. 5). Parameters $P_{1}$ and $P_{2}$ were provided by the differential pressure sensor manufacturer:

$$
\Delta P_{C}=P_{1} \times \Delta P+P_{2}
$$

where

$$
\begin{aligned}
& \Delta P_{C}=\text { calibrated differential pressure }(\mathrm{Pa}) \\
& P_{1}=\text { calibration slope }\left(\mathrm{Pa} \mathrm{mV} \mathrm{V}^{-1}\right) \\
& P_{2}=\text { calibration offset }(\mathrm{Pa}) .
\end{aligned}
$$

\section{Calibration}

Six FANS-G4 units (serial numbers FANS-G4-30-01, FANS-G4-48-01, FANS-G4-48-02, FANS-G4-54-01, FANS-G4-54-02, and FANS-G4-54-03) were calibrated at the UIUC BESS Laboratory. The FANS-G4-30 and FANSG4-48 units were mounted at the wind tunnel outlet. The larger FANS-G4-54 units required the addition of a short, tapered transition to connect the unit to the tunnel inlet orifice. Actual airflow, which was considered to be the airflow as measured with the BESS Laboratory wind tunnel, was determined using a manometer across a bulkhead with a large number of calibrated flow nozzles inside the wind tunnel. The recording of an actual airflow measurement and the average airflow from two simultaneous traverses reported by the FANS-G4 PC software were considered to be a calibration point. A minimum of ten calibration points were collected, ranging from 0 to $15,000 \mathrm{~m}^{3} \mathrm{~h}^{-1}$ for a FANS-G4-30, from 0 to $56,000 \mathrm{~m}^{3} \mathrm{~h}^{-1}$ for a FANS-G4-40, and from 0 to $56,000 \mathrm{~m}^{3} \mathrm{~h}^{-1}$ for a FANS-G4-54. A linear regression model was used to represent the relationship between BESS Laboratory airflow and FANS-G4 airflow. The standard error of regression $\left(\mathrm{SE}_{y \mid x}\right)$ and the $95 \%$ prediction interval (PI) for each unit were calculated. The inverted regression equation was used for subsequent field use of each FANS, using the calibration coefficients.

\section{RESULTS AND DISCUSSION \\ General Performance Specifications}

A test typically produced 590,950 , or 1070 individual rpm measurements per anemometer for the FANS-G4-30, FANS-G4-48, and FANS-G4-54 units, respectively, which was approximately $18 \%$ fewer than for FANS-G3 units. The sampling interval differed in spacing between the horizontal and vertical directions. The horizontal sampling interval was determined by the spacing of the anemometers along the anemometer rack and ranged from 21.6 to $25.1 \mathrm{~cm}$ for the smallest and largest units, respectively. The vertical sampling interval was a combination of the $12.5 \mathrm{~Hz}$ data sampling rate and the $1.5 \mathrm{~cm} \mathrm{~s}^{-1}$ travel speed, resulting in a physical spacing between samples of $0.13 \mathrm{~cm}$.

\section{RAW DATa Visualization}

The spatial resolution of velocity across a fan can be visualized in two dimensions to better understand the difference in the sampling interval between the two measurement axes. In figure 9, two figures from Sama et al. (2012a) have been combined to illustrate how the raw data were distributed across the FANS inlet and what that data looked like when processed into an air velocity contour map. The data were collected with a FANS-G3 unit using the FANS-G4 PC software on a ventilation fan that was running immediately adjacent to a second ventilation fan, which resulted in an area of low air velocity on the adjacent side. The visualization process illustrates how the airflow distribution of an individual fan is affected by a gradient in static pressure across the inlet. The sample plot (fig. 9a) shows the individual air velocity measurements in counting order along both spatial axes. The position plot (fig. 9b) shows the structure of air velocity across the FANS unit in physical dimensions. The number of samples in the vertical direction exceeded the number of samples in the horizontal direction by a factor of 260. Noise, generated by changes in instantaneous building static pressure, the FANS unit electromechanical system, and the fan under test, is clearly visible in the sample plot. However, the large number of samples collected over the sampling period ensured that these sources of noise were smoothed in the average volumetric airflow measurement.

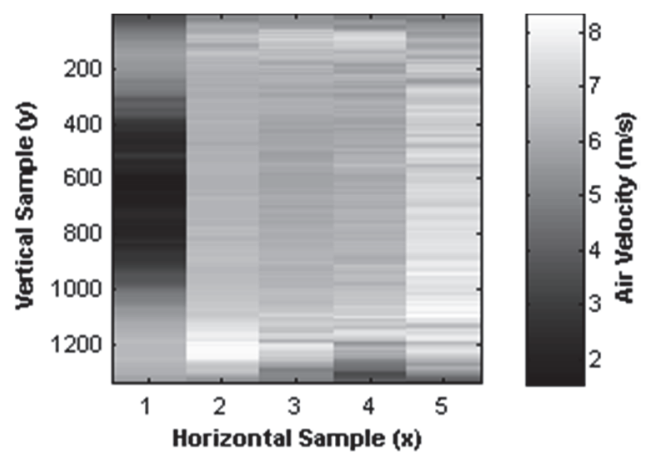

(a)

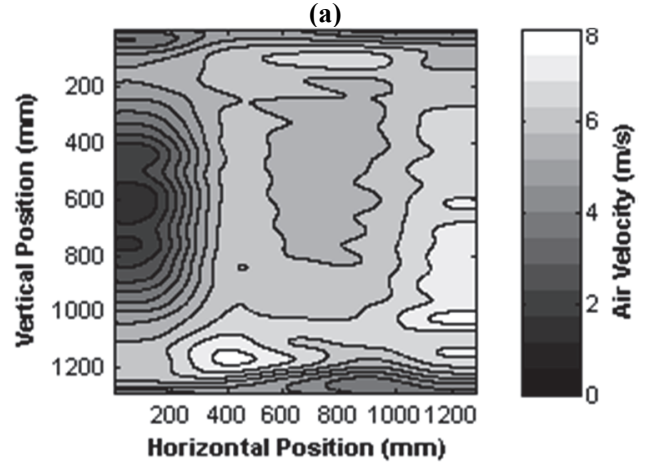

(b)

Figure 9. Visualization of FANS raw data from Sama et al. (2012a) showing (a) individual air velocity measurements on a sample scale and (b) contour plot of air velocity measurements on a dimension scale. 

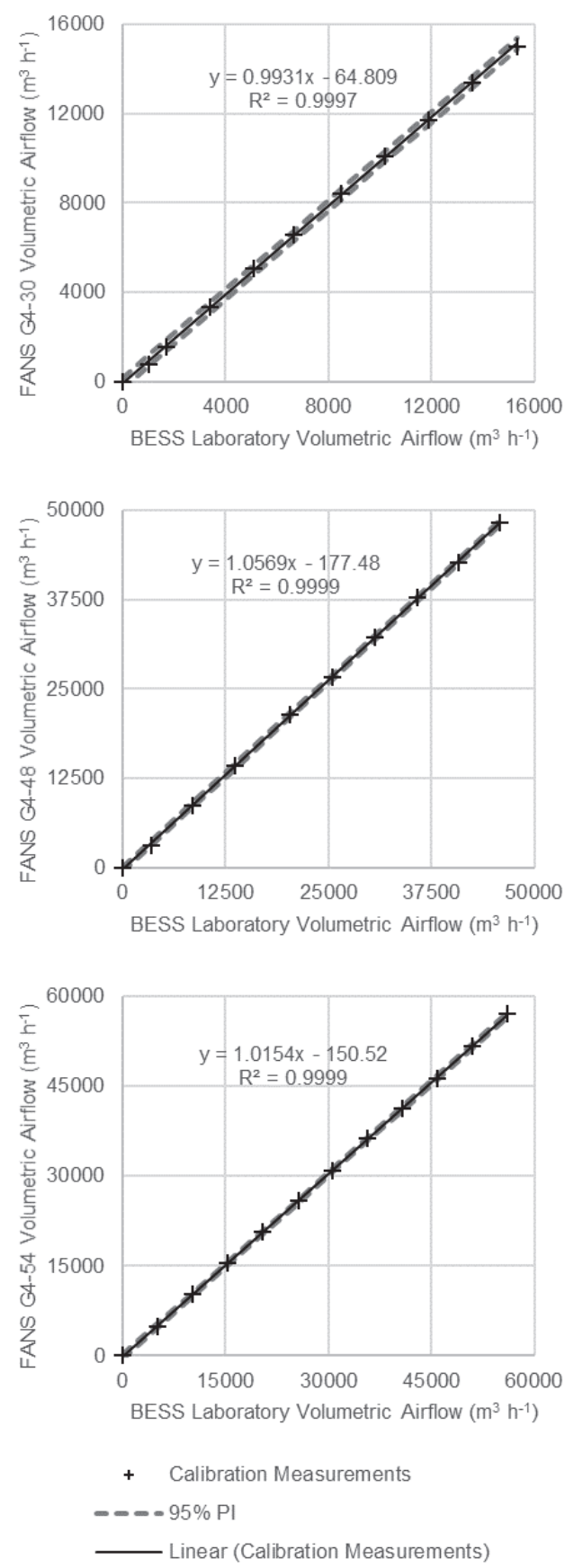

Figure 10. Calibration results for FANS-G4 airflow measurements using BESS Laboratory airflow as the reference standard. Linear regressions and $\mathbf{9 5 \%}$ prediction intervals for three FANS sizes are shown.

\section{Calibration Results}

Regression models and prediction intervals for all three FANS-G4 unit sizes are shown in figure 10. The FANS-G4 response to actual airflow was linear $\left(\mathrm{R}^{2}>0.999\right)$, and the prediction interval never exceeded a $750 \mathrm{~m}^{3} \mathrm{~h}^{-1}$ difference with any calibration point. The FANS-G4 calibration equation was obtained directly from the regression model by solving for $x$ in the regression equation. Note that the PC software required entering the calibration coefficients in units of $\mathrm{ft}^{3} \mathrm{~min}^{-1}(\mathrm{cfm})$ and inches of water $\left(\right.$ in. $\left.\mathrm{H}_{2} \mathrm{O}\right)$, which
Table 1. Airflow calibration results for six FANS-G4 units.

\begin{tabular}{ccccc}
\hline FANS Unit & Slope & $\begin{array}{c}\text { Intercept } \\
\left(\mathrm{m}^{3} \mathrm{~h}^{-1}\right)\end{array}$ & $\begin{array}{c}\mathrm{SE}_{y \mid x}[\mathrm{a}] \\
\left(\mathrm{m}^{3} \mathrm{~h}^{-1}\right)\end{array}$ & $\begin{array}{c}\mathrm{SE}_{x[y}^{[b]} \\
\left(\mathrm{m}^{3} \mathrm{~h}^{-1}\right)\end{array}$ \\
\hline FANS-G4-30-01 & 1.007 & 65.3 & 98.7 & 99.4 \\
FANS-G4-48-01 & 0.946 & 168 & 160 & 151 \\
FANS-G4-48-02 & 0.978 & 348 & 168 & 165 \\
FANS-G4-54-01 & 0.985 & 148 & 151 & 148 \\
FANS-G4-54-02 & 0.972 & 214 & 150 & 146 \\
FANS-G4-54-03 & 0.975 & 450 & 210 & 205 \\
\hline
\end{tabular}

[a] Standard error of regression of $y$ (FANS reading) on $x$ (BESS airflow).

[b] Standard error of calibration equation (inverted regression).

was the default output from the BESS Laboratory. The calibration range for each FANS-G4 was consistent with the volumetric airflow and static pressures expected in field operational conditions.

The calibration results from all five FANS-G4 units are summarized in table 1. The FANS-G4-48 and FANS-G4-54 units all overestimated actual airflow, while the FANS-G430 underestimated actual airflow, which was likely due to variability in the FANS-G4 inlet dimensions. Intercepts ranged from 65 to $450 \mathrm{~m}^{3} \mathrm{~h}^{-1}$ and were a result of a consistent offset produced by measurement error in the embedded controller hardware, i.e., the FANS-G4 reported a small anemometer speed even when the anemometers were static. The source of this error was likely due to the difference in $\mathrm{A} / \mathrm{D}$ input impedance between the anemometers and the reference voltage. The standard error of predicted airflow when using a FANS-G4 unit in the field $\left(\mathrm{SE}_{x \mid y}\right)$ was derived from the calibration standard error $\left(\mathrm{SE}_{y \mid x}\right)$ using the regression model slope. Both standard error measures were nearly identical due to unity slope and ranged between 99 and $210 \mathrm{~m}^{3} \mathrm{~h}^{-1}$, representing $\mathrm{FS}$ errors of $0.6 \%, 0.3 \%$, and $0.4 \%$ for the FANS-G4-30, FANS-G4-48, and FANS-G4-54 units, respectively. FANS-G4 users should consider the standard error of predicted airflow when computing uncertainty in a measurand, such as emissions rate, from the FANS-G4 airflow measurement.

\section{CONCLUSIONS}

The FANS hardware and software control components were updated from previous generations to add wireless communication capability, higher data transfer rate, faster travel speed, and safer operation. Six FANS-G4 units were calibrated at the UIUC BESS Laboratory. Results showed that the FANS-G4 response to airflow was highly linear and resulted in a standard error of prediction of less than $205 \mathrm{~m}^{3}$ $\mathrm{h}^{-1}$, or $0.6 \% \mathrm{FS}$ error. The low error and portability of the FANS-G4 provide an accurate method for generating in situ fan performance curves for quantifying ventilation rates.

Future recommended improvements include: (1) reduce the number of anemometers to one by adding a second axis of motion orthogonal to the current axis, thus reducing the overall cost; (2) further increase the travel speed and data rate to reduce the measurement duration while maintaining the existing number of individual measurements; (3) include a preconfigured laptop with the FANS-G4 to eliminate potential software compatibility issues; (4) develop a mobile application for deploying FANS-G4 units using a cellphone or tablet device; and (5) evaluate the calibration stability of 
FANS-G4 units and determine an appropriate schedule for recalibration.

\section{ACKNOWLEDGEMENTS}

This is Publication No. 17-05-031 of the Kentucky Agricultural Experiment Station and is published with the approval of the Director.

The authors wish to express gratitude to Will Adams, Lee Rechtin, Brett Childers, and Ed Hutchens at the UK Agricultural Machinery Research Laboratory for their mechanical design and fabrication support and Steve Ford at the UIUC BESS Laboratory for his assistance with calibrating the FANS-G4. Special thanks are extended to the FANS users across the U.S. who provided feedback on operation and suggestions for improvements incorporated into the FANSG4 design.

\section{REFERENCES}

Burns, R. T., Li, H., Moody, L., Xin, H., Gates, R. S., Overhults, D. G., \& Earnest, J. W. (2008b). Quantification of particulate emissions from broiler houses in the southeastern United States. In Proc. 8th Intl. Livestock Environ. Symp. (pp. 101-109), St. Joseph, MI: ASABE.

Burns, R. T., Li, H., Xin, H., Gates, R. S., Overhults, D. G., Earnest, J. W., \& Moody, L. (2008a). Greenhouse gas (GHG) emissions from broiler houses in the southeastern United States. ASABE Paper No. 084649. St. Joseph, MI: ASABE.

Burns, R. T., Xin, H., Gates, R. S., Li, H., Overhults, D. G., Moody, L., \& Earnest, J. W. (2007). Ammonia emissions from poultry broiler systems in the southeastern United States. In Proc. Intl. Symp. Air Quality and Waste Mgmt. for Agriculture (pp. 15-19). St. Joseph, MI: ASABE.

Calvet, S., Gates, R. S., Zhang, G., Estelles, F., Ogink, N. W., Pedersen, S., \& Berckmans, D. (2013). Measuring gas emissions from livestock buildings: A review on uncertainty analysis and error sources. Biosyst. Eng., 116(3), 221-231. http://dx.doi.org/10.1016/j.biosystemseng.2012.11.004

Cortus, E. L., Jacobson, L. D., Hetchler, B. P., \& Heber, A. J. (2012). Emission monitoring methodology at a NAEMS dairy site, with an assessment of the uncertainty of measured ventilation rates. In Proc. 9th Intl. Livestock Environ. Symp. St. Joseph, MI: ASABE. https://dx.doi.org/10.13031/2013.41578

Gates, R. S., Xin, H., Casey, K. D., Liang, Y., \& Wheeler, E. F. (2005). Method for measuring ammonia emissions from poultry houses. J. Appl. Poultry Res., 14(3), 622-634. https://dx.doi.org/10.1093/japr/14.3.622

Gates, R., Casey, K. D., Xin, H., \& Burns, R. T. (2009). Building emissions uncertainty estimates. Trans. ASABE, 52(4), 13451351. https://dx.doi.org/10.13031/2013.27784

Gates, R., Casey, K. D., Xin, H., Wheeler, E. F., \& Simmons, J. D. (2004). Fan Assessment Numeration System (FANS) design and calibration specifications. Trans. ASAE, 47(5), 1709-1715. https://dx.doi.org/10.13031/2013.17613

Hayes, M., Xin, H., Li, H., Shepherd, T., Zhao, Y., \& Stinn, J. (2013). Ammonia, greenhouse gas, and particulate matter emissions of aviary layer houses in the midwestern U.S. Trans. ASABE, 56(5), 1921-1932. https://dx.doi.org/10.13031/trans.56.10053

Heber, A. J., Bogan, B. W., Ni, J. Q., Lim, T. T., Cortus, E. L., Ramirez-Dorronsoro, J. C., ... Casey, K. D. (2009). The National Air Eemissions Monitoring Study: Overview of barn sources. In Proc. 8th Intl. Livestock Environ. Symp. (pp. 199-205). St. Joseph, MI: ASABE.
Ji, B., Zheng, W., Gates, R. S., \& Green, A. R. (2016). Design and performance evaluation of the upgraded portable monitoring unit for air quality in animal housing. Comput. Electron. Agric., 124, 132-140. http://dx.doi.org/10.1016/j.compag.2016.03.030

Li, H., Burns, R. T., Xin, H., Gates, R. S., Trabue, S., Overhults, D. G., ... Earnest, J. W. (2008). Hydrogen sulfide and non-methane hydrocarbon emissions from broiler houses in the southeastern United States. ASABE Paper No. 084417. St. Joseph, MI: ASABE.

Li, H., Xin, H., Li, H., \& Burns, R. T. (2009). Upstream vs. downstream placement of FANS device to determine ventilation fan performance in situ. Trans. ASABE, 52(6), 2087-2090. https://dx.doi.org/10.13031/2013.29211

Liang, Y., Bautista, R., \& Costello, T. A. (2016). Validating a multi-port, averaging pitot tube for measuring fan airflow rates. Appl. Eng. Agric., 32(4), 409-415. https://dx.doi.org/10.13031/aea.32.11411

Liang, Y., Xin, H., Wheeler, E. F., Gates, R., Li, H., Zajaczkowski, F. J., ... Zajaczkowski, F. J. (2005). Ammonia emissions from U.S.. laying hen houses in Iowa and Pennsylvania. Trans. ASAE, 48(5), 1927-1941.https://dx.doi.org/10.13031/2013.20002

Lopes, I. M., Overhults, D. G., Morello, G. M., Earnest Jr., J. W., Gates, R. S., Pescatore, A. J., ... Miller, M. (2010). Assessing air leakage in commercial broiler houses. ASABE Paper No. 1009236. St. Joseph, MI: ASABE. https://dx.doi.org/10.13031/2013.31998

Moody, L. B., Li, H., Burns, R. T., Xin, H., Gates, R. S., Hoff, S. J., \& Overhults, D. G. (2008). A quality assurance project plan for monitoring gaseous and particulate matter emissions from broiler housing. Published as a special ASABE peer-reviewed publication. St. Joseph, MI: ASABE.

Morello, G. M., Overhults D., G., Day, G. B., Gates R., S., Lopes I., M., \& Earnest Jr., J. W. (2014). Using the Fan Assessment Numeration System (FANS) in situ: A procedure for minimizing errors during fan tests. Trans. ASABE, 57(1), 199-209. https://dx.doi.org/10.13031/trans.57.10190

Person, H. L., Jacobson, L. D., \& Jordan, K. A. (1979). Effect of dirt, louvers, and other attachments on fan performance. Trans. ASAE, 22(3), 612-616. https://dx.doi.org/10.13031/2013.35071

Purswell, J. L., Luck, B. D., \& Davis, J. D. (2014). Effect of air deflectors on fan performance in tunnel-ventilated broiler houses with a dropped ceiling. Appl. Eng. Agric., 30(3), 471-475. https://dx.doi.org/10.13031/aea.30.10467

Sama, M. P., Gates, R. S., Adams, W. C., Day, G. B., \& King, C. L. (2008). Fan Assessment Numeration System (FANS) scaling and upgrades. ASABE Paper No. 084723. St. Joseph, MI: ASABE.

Sama, M. P., Morello, G. M., Lopes, I. M., Day, G. B., \& Overhults, D. G. (2012a). Visualizing airflow using the Fan Assessment Numeration System (FANS). ASABE Paper No. 121337883. St. Joseph, MI: ASABE.

Sama, M. P., Pepple, L. M., Day, G. B., Overhults, D. G., Morello, G. M., Lopes, I. M., ... Gates, R. S. (2012b). Calibration drift assessment and upgrades to the Fan Assessment Numeration System (FANS). ASABE Paper No. 121337770. St. Joseph, MI: ASABE.

Simmons, J. D., Hannigan, T. E., \& Lott, B. D. (1998a). A portable anemometer to determine the output of large in-place ventilation fans. Appl. Eng. Agric., 14(6), 649-653. https://dx.doi.org/10.13031/2013.19425

Simmons, J. D., Lott, B. D., \& Hannigan, T. E. (1998b). Minimum distance between ventilation fans in adjacent walls of tunnel ventilated broiler houses. Appl. Eng. Agric., 14(5), 533-535. https://dx.doi.org/10.13031/2013.19411

Trabue, S., Scoggin, K., McConnell, L. L., Li, H., Turner, A., Burns, R. T., ... Hatfield, J. (2013). Performance of commercial 
non-methane hydrocarbon analyzers in monitoring oxygenated volatile organic compounds emitted from animal feeding operations. J. Air Waste Mgmt. Assoc., 63(10), 1163-1172. https://dx.doi.org/10.1080/10962247.2013.804464

Wheeler, E. F., Casey, K. D., Gates, R., Xin, H., Zajaczkowski, F. J., Topper, P. A., ... Pescatore, A. J. (2006). Ammonia emissions from twelve U.S. broiler chicken houses. Trans. ASABE, 49(5), 1495-1512. https://dx.doi.org/10.13031/2013.22042

Zhi, Z., Gates, R. S., Zhirong, Z., \& Xiohui, H. (2015). Evaluation of ventilation performance and energy efficiency of greenhouse fans. Intl. J. Agric. Biol. Eng., 8(1), 103-110.

https://dx.doi.org/10.3965/j-ijabe.20150801.014 